\title{
Morfometria e beneficiamento de sementes de Schizolobium parahyba (Vell.) Blake var. parahyba
}

\author{
Felipe Augusto Hanzen ${ }^{\text {a }}$ Joao Alexandre Lopes Dranski ${ }^{\mathrm{a} *}$ (1) \\ ${ }^{\mathrm{a}}$ Faculdade Educacional de Medianeira, Brasil \\ *Autor correspondente (joaodranski@yahoo.com.br)
}

\section{N F O}

\section{Keywords}

guapuruvú

seed classification

sieve retention

\section{Palavras-chaves guapuruvú \\ classificação de \\ sementes \\ retenção em peneiras}

\begin{abstract}
A B S T R A C T
Morphometry and seed beneficiation of Schizolobium parahyba (Vell.) Blake var. parahyba. The objective of this work was to evaluate morphometry and seed beneficiation of Schizolobium parahyba. Were used seeds from the three tree matrices located in a ciliary domain area in the municipality of Medianeira - PR. Casually separated four repetitions from 100 seeds. Circular sieve sieves were used, with perfurations of $14 \mathrm{~mm}$ to $18 \mathrm{~mm}$, and oblong sieves, with perfurations of $4 \times 22 \mathrm{~mm}$ to $5 \times 22 \mathrm{~mm}$. The test took place so that the seeds were arranged on the sieves in descending order and subjected to manual agitation. After obtaining morphometric data, descriptive statistical procedures have been applied and histograms were built of frequency distribution and class histograms according to the type and size of the sieve. The proportions were tested with Qui-square test at the level of 5\% of error probability in the proportion of observed and expected seeds within the class intervals. The average morphometric and mass parameters, as well as the uniformity of the retained seeds as a function of drill and sieve type, were submitted to variance analysis and when differences of differences were compared by Dunnett test at $5 \%$ of error probability. The results obtained indicated the circular sieves as the best for processing of guapuruvú seeds with the fact that the best basis for separation was width.
\end{abstract}

\section{R E S U M O}

O objetivo do presente trabalho foi avaliar a morfometria e o beneficiamento de sementes Schizolobium parahyba. Foram utilizadas sementes oriundas de coleta realizada em três árvores matrizes situadas em uma área de domínio ciliar na região do município de Medianeira - PR. Separaram-se casualmente quatro repetições de 100 sementes, das quais foram mensurados o comprimento, a largura, a espessura e a massa. Foram utilizadas peneiras de crivo circular, com perfurações de $14 \mathrm{~mm}$ a $18 \mathrm{~mm}$, e peneiras de crivo oblongo, com perfurações de 4 × $22 \mathrm{~mm}$ e 5 × $22 \mathrm{~mm}$. O teste ocorreu de forma que as sementes foram dispostas sobre as peneiras em ordem decrescente e submetidas a agitação manual. Após a peneiração computou-se os dados morfométricos e de massa das sementes retidas e aplicaram-se procedimentos da estatística descritiva e construíram-se histogramas de distribuição de frequências com o tipo e tamanho do crivo. Comparou-se pelo teste de Qui-quadrado a 5\% de probabilidade de erro a proporção de sementes observadas e esperadas dentro dos intervalos de classe. As médias dos parâmetros morfométricos e de massa, bem como a uniformidade de sementes retidas em função da furação e tipo de peneira foram submetidas a análise de variância e quando da evidência de diferenças significativas as médias foram comparadas pelo teste Dunnett a 5\% de probabilidade de erro. Os resultados obtidos indicaram que peneiras de crivo circular como as melhores para o beneficiamento de sementes de guapuruvú constatando-se que a melhor base para separação no peneiramento foi a largura. 


\section{INTRODUÇÃO}

A variação no tamanho das sementes de espécies florestais é grande devido à influência de fatores endógenos, bióticos e abióticos. Logo a análise da morfometria de sementes auxilia tanto na detecção de variabilidade entre e dentro de populações como na definição de relações entre a variabilidade e o meio ambiente e sua influência (Cruz e Carvalho, 2003; Gusmão et al., 2006; Freire et al., 2015; Silva et al., 2015).

A quantidade de substâncias de reservas encontradas nas sementes estão associadas principalmente a morfologia dos cotilédones, o que afeta significativamente a germinação e o estabelecimento das mudas (Bewley et al., 2013), logo, sementes pequenas garantem melhores condições de dispersão, enquanto sementes grandes normalmente apresentam maiores reservas de suprimentos para o estabelecimento das plântulas (Malavasi e Malavasi, 2001).

A determinação e padronização de tamanhos das sementes variam conforme as necessidades e objetivos de uso para cada espécie (Biruel et al., 2010). Em se tratando de produção vegetal, diversos trabalhos avaliaram o tamanho das sementes no desenvolvimento de espécies florestais e constataram que sementes com maiores dimensões originaram mudas de tamanhos superiores, enquanto sementes de tamanho inferior geraram plantas de menor porte e de qualidade inferior (Antunes et al., 2012; Pagliarini et al., 2014; Silva et al., 2015; Dranski et al., 2019) e isso afeta o estabelecimento de povoamentos florestais (Tsakaldimi et al., 2013).

$\mathrm{O}$ beneficiamento de sementes procura melhorar o potencial fisiológico de um lote de sementes, garantindo condições apropriadas visando melhor armazenamento e semeadura. A separação de sementes pode ocorrer de diversas formas, dentre elas a classificação por peneiras utiliza-se características morfométricas, levando em consideração a parâmetros que melhor permite homogeneizar o tamanho e/ou a massa de sementes.

A espécie Schizolobium parahyba (Vell.) Blake var. parahyba pertence à família Fabaceae, nativa da Mata Atlântica, com ocorrência nas diversas formações florestais deste bioma. É uma espécie de rápido crescimento, seletiva higrófita, ocupando principalmente planícies aluviais, ao longo de rios e no início de encostas (Carvalho, 2005). Além de sua importância ecológica, comumente utilizada para reflorestamento de áreas degradadas (Resende e Pinto, 2013; Gonzalo et al., 2015), a espécie possui relevante importância econômica, pois sua madeira pode ser empregada para produção de painéis de aglomerados (Trianoski et al., 2011),
Não se tem conhecimento de pesquisas realizadas com sementes de Schizolobium parahyba visando sua separação e classificação, indicando a aptidão de tipos de peneiras a ser utilizadas na classificação das sementes. Desta forma, o presente trabalho teve por objetivo avaliar a morfometria e o beneficiamento de sementes Schizolobium parahyba (Vell.) Blake var. parahyba.

\section{MATERIAL E MÉTODOS}

O experimento foi conduzido no Laboratório de Sementes da Faculdade Educacional de Medianeira - UDC Medianeira, situada nas coordenadas de $25^{\circ} 29^{\prime} 63^{\prime \prime} \mathrm{S}$ e $54^{\circ} 09^{\prime} 59^{\prime \prime} \mathrm{O}$, a uma altitude de $420 \mathrm{~m}$.

A execução do experimento compreendeu os meses de setembro e outubro de 2019. Foram utilizadas sementes de Schizolobium parahyba oriundas de coleta realizada no mês de agosto de 2019, em três árvores matrizes situadas em uma área de domínio ciliar na região do município de Medianeira, PR, sob coordenadas geográficas de $25^{\circ} 17^{\prime} 37,9^{\prime \prime} \mathrm{S}$ e $54^{\circ} 07^{\prime} 09,5^{\prime \prime} \mathrm{O}$.

O clima do município de Medianeira é subtropical úmido ou mesotérmico, com presença de verão e inverno bem definidos e possibilidades de geadas e chuvas em todos os meses do ano. A temperatura média no mês mais quente ultrapassa os $26^{\circ} \mathrm{C}$ e no mês mais frio, a temperatura média é inferior a $18{ }^{\circ} \mathrm{C}$. O período de maior índice pluviométrico ocorre entre setembro a janeiro (Nitsche et al., 2019).

Após a coleta, as sementes foram extraídas dos frutos com coloração do endocarpo predominantemente marrom e possuíam o endocarpo papiráceo desprendido do pericarpo (Pietrobom e Oliveira, 2004), sendo retiradas manualmente do endocarpo, homogeneizadas, imersas em solução de hipoclorito de sódio a $0,5 \%$ por $5 \mathrm{mim}$ e postas a secar a sombra por 7 dias. Posteriormente as sementes foram armazenadas em frascos de polipropileno, a temperatura ambiente, resguardadas da exposição à luz e umidade.

Foram separadas casualmente quatro repetições de 100 sementes. Em cada repetição as sementes foram enumeradas e posteriormente foram realizadas aferições de comprimento, largura, espessura e massa utilizando paquímetro digital e balança analítica. O comprimento referiu-se a maior distância paralela ao hilo, enquanto que a largura referiu-se a maior distância transversal ao cotilédone e para a espessura foi a maior distância paralela ao cotilédone.

Posteriormente, empregou-se um teste para classificação de sementes por peneiração. Foram utilizadas peneiras de crivo circular, com perfura- 
ções de $14 \mathrm{~mm}$ a $18 \mathrm{~mm}$, e peneiras de crivo oblongo, com perfurações de 4 x $22 \mathrm{~mm}$ e 5 x 22 $\mathrm{mm}$. O teste ocorreu de forma que as sementes foram dispostas sobre as peneiras em ordem decrescente, ou seja, da peneira de crivo maior para a de crivo menor, sendo submetidas à agitação manual e retidas conforme o tamanho.

Após a obtenção dos dados morfométricos, aplicaram-se procedimentos da estatística descritiva e construiu-se um histograma de distribuição de frequências, cujo número de classes foi com base na regra de Sturges (Sturges, 1926).

Após a classificação por peneiras, construíramse histogramas, cujas classes foram de acordo com o tipo e tamanho do crivo. Comparou-se a proporção de sementes retidas pelo teste de Quiquadrado ao nível de 5\% de probabilidade de erro, à aderência sobre o que naturalmente espera ser observado, levando em consideração a largura para sementes retidas em crivos circulares e a espessura para as retidas em crivos oblongos.

Foram contrastadas as médias dos parâmetros morfométricos e de massa de sementes sobre o observado sem classificação (controle). Nesta etapa, após as análises dos pressupostos de normalidade e homogeneidade dos erros experimentais, os dados foram submetidos à análise de variância e as médias comparadas pelo teste Dunnett a 5\% de probabilidade de erro (Sigmaplot, 2011).

Por fim, para as sementes retidas em cada tipo de crivo foram calculados os coeficientes de variação de cada repetição e para cada parâmetro, que retrata a uniformidade das sementes dentro de cada classe e foram contrastados sobre o observado sem classificação (controle). Nesta etapa, após as análises dos pressupostos de normalidade e homogeneidade dos erros experimentais, os dados foram submetidos à análise de variância e as médias comparadas pelo teste Dunnett a $5 \%$ de probabilidade de erro (Sigmaplot, 2011).

\section{RESULTADOS E DISCUSSÃO}

A partir da tabela 1 pode-se visualizar os dados obtidos para a morfometria das sementes de Schizolobium parahyba. As sementes sem classificação apresentaram em média o comprimento de $27,75 \mathrm{~mm}$ com largura de $16,72 \mathrm{~mm}$ e espessura de $4,58 \mathrm{~mm}$, com massa de $1,70 \mathrm{~g}$. Maiores valores de amplitude foram observados para o comprimento $(11,15 \mathrm{~mm})$ e para a largura das sementes $(5,5 \mathrm{~mm})$.

Tabela 1 - Morfometria de sementes de Schizolobium parahyba.

\begin{tabular}{|c|c|c|c|c|}
\hline \multirow{2}{*}{ Parâmetros } & Comprimento & Largura & Espessura & \multirow{2}{*}{$\begin{array}{c}\text { Massa } \\
----\mathrm{g}^{-1}----\end{array}$} \\
\hline & \multicolumn{3}{|c|}{------------ mm ----------- } & \\
\hline Média & 27,75 & 16,72 & 4,58 & 1,70 \\
\hline Amplitude & 11,15 & 5,50 & 1,99 & 1,42 \\
\hline Desvio padrão & 1,19 & 0,67 & 0,32 & 0,21 \\
\hline $\mathrm{CV}(\%)$ & 4,30 & 4,00 & 7,05 & 12,24 \\
\hline
\end{tabular}

Em que: $n=400$ sementes

Nota-se também que o parâmetro morfométrico que possuiu maior desvio padrão relativo foi a espessura (Tabela 1), apresentando um coeficiente de variação de $7,05 \%$. Já para a massa de sementes, o desvio padrão relativo foi maior que o encontrado para a forma, cujo coeficiente de variação foi de $12,24 \%$.

Por meio destas informações, nota-se que a espessura possuiu variação, mas com pouca amplitude, o que limita o beneficiamento por peneiramento, pois as furações de peneiras de crivo oblongo são comercializadas com largura que variam de $0,5 \mathrm{~mm}$. O comprimento expressou valores razoáveis para amplitude bem como para desvio padrão, porém sua separação não se aplica por peneiração, mas sim por cilindros rotativos alveolados, enquanto que a largura apresentou valores consideráveis em amplitude e coeficiente de variação, possibilitando sua utilização como uma boa base de separação por peneiramento. Já a classificação de sementes pelo peso pode ser reali- zada por meio de mesa densimétrica (Peske e Labbé, 2012).

Ao aplicar o fator forma circular de Grum, a qual leva em consideração a área de um objeto (neste estudo tomado como base a largura), dividido pelo quadrado de sua maior dimensão (comprimento), as sementes foram classificadas como achatadas. Ao aplicar a razão de aspectos, que é a razão entre a menor dimensão (espessura) e a maior dimensão (comprimento), as sementes foram então classificadas como alongadas. Portanto as sementes de Schizolobium parahyba podem ser classificadas como sementes alongada-achatadas.

A partir da figura 1, pode-se visualizar a distribuição de frequências das variáveis analisadas para as sementes de Schizolobium parahyba. Para o comprimento (Figura 1a) observa-se uma assimetria negativa $(\mathrm{A}=-0,50)$ da distribuição dos comprimentos, o que representa que $50 \%$ ou mais das sementes situaram-se acima do comprimento mediano, ou seja, estão próximos aos maiores 
valores encontrados para o comprimento e com alta homogeneidade, devido ao alto valor calculado para o coeficiente de curtose $(\mathrm{K}=3,96)$. Para largura (Figura 1b), houve uma distribuição simétrica $(\mathrm{A}=0,04)$, representando apenas $4 \%$ das sementes abaixo da largura média. $\mathrm{O}$ coeficiente de curtose calculado foi positivo $(\mathrm{K}=1,22)$ caracterizando uma distribuição mais ponderada e uma cauda mais longa.

A espessura por sua vez (Figura 1c), apresentou uma distribuição simétrica, a semelhança do comprimento, onde o coeficiente de assimetria apon-
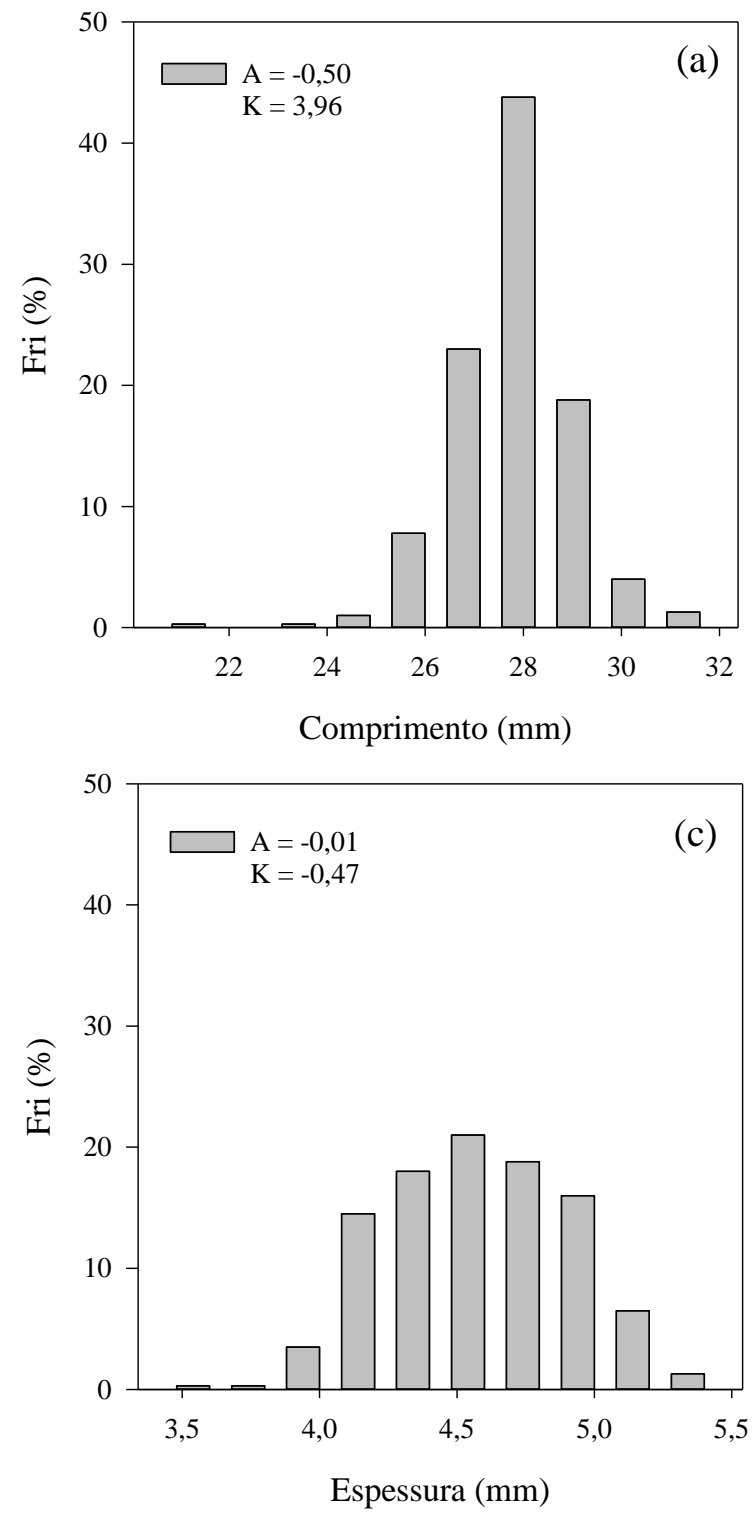

tou valor próximo à simetria $(\mathrm{A}=-0,01)$, com aproximadamente $1 \%$ das sementes com espessura acima da média, porém o coeficiente de curtose apresentou uma variação um pouco maior $(\mathrm{K}=$ $0,47)$. Por fim, na distribuição obtida para os valores de massa (Figura 1d), observou-se também assimetria negativa $(A=-0,13)$, grafando que $13 \%$ das sementes apresentaram massa acima da média e coeficiente de curtose também negativo ( $K=$ $0,19)$, determinando uma distribuição mais variável.
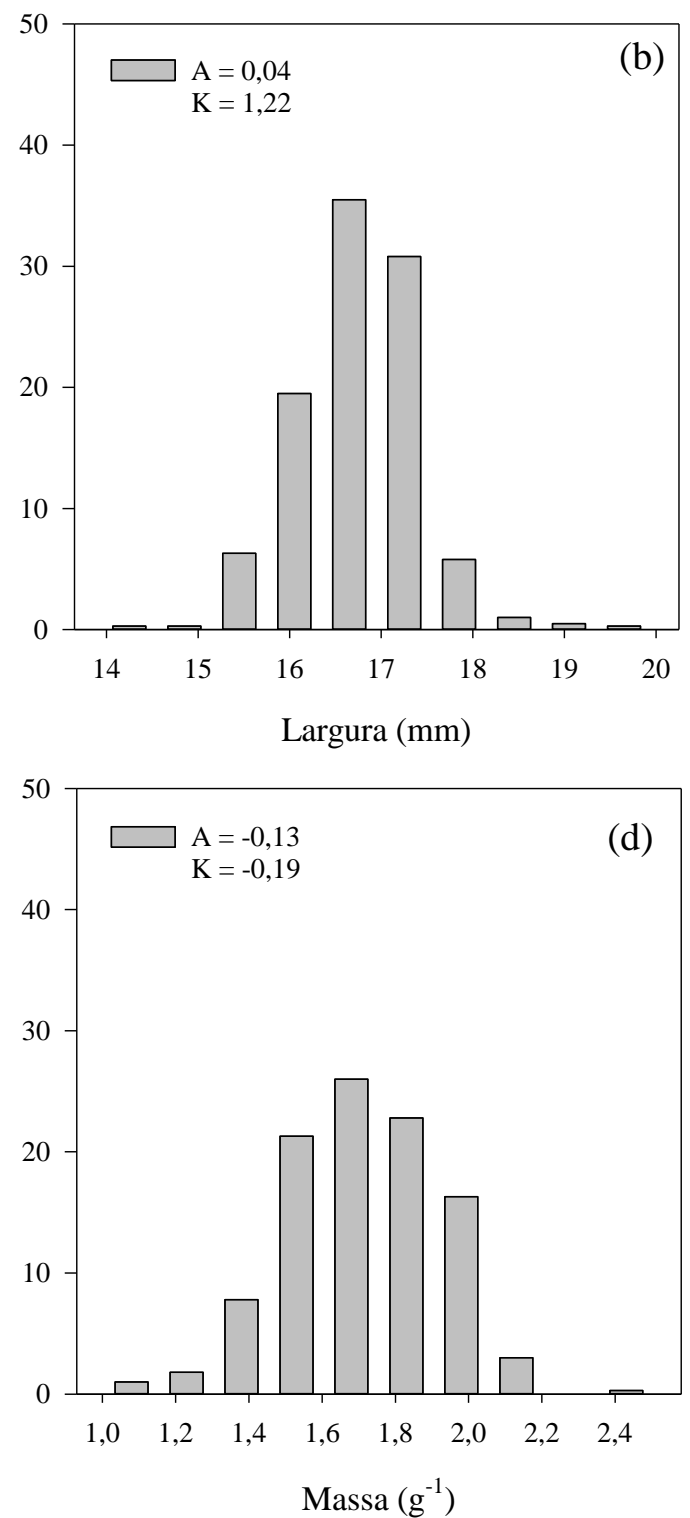

Legenda: A: coeficiente de assimetria; K: coeficiente de curtose; Valores nos eixos X representam o ponto médio da classe.

Figura 1 - Distribuição de frequências relativas ao comprimento (a), a largura (b), a espessura (c) e a massa (d) de sementes de Schizolobium parahyba

A partir da figura 2, pode-se visualizar a distribuição de frequências após classificação em peneiras e com base na largura ou espessura das semen- tes. Ao comparar as proporções de sementes retidas em peneiras de crivo circular sobre aquilo que se espera encontrar naturalmente dentro dos limi- 
tes do crivo (Figura 2a), observa-se não haver evidências de diferenças significativas ( $p>0,05$ ). Portanto ao classificar sementes de Schizolobium

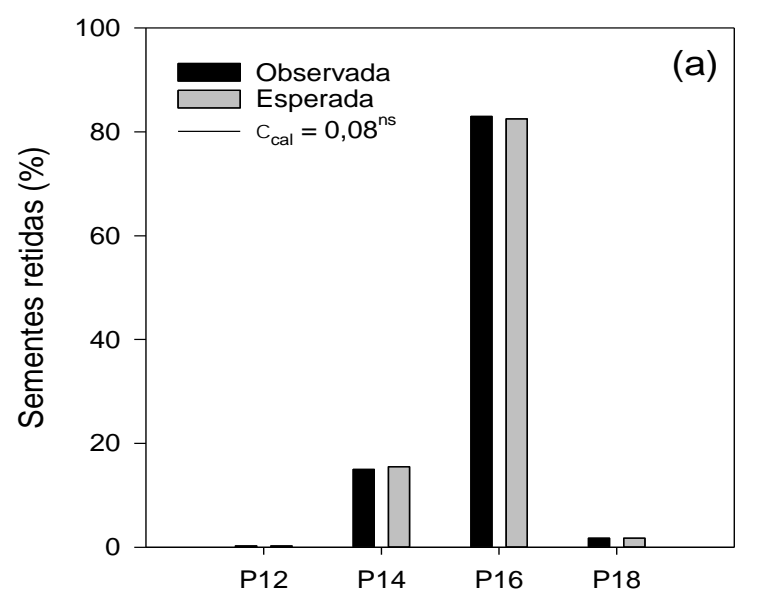

Penerira de crivo circular $(\mathrm{mm})$ parahyba por meio de peneiras de crivo circular o observado será estatisticamente semelhante ao esperado.

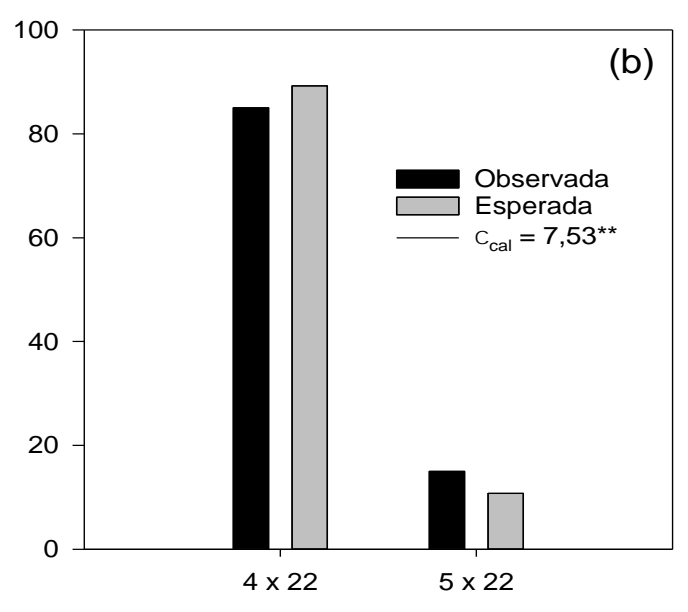

Peneira de crivo oblongo $(\mathrm{mm})$

Legenda: Em que: ${ }^{* *}$ ns Não significativo ou significativo a $95 \%$ de confiança pelo teste Qui-quadrado. n= 400 sementes.

Figura 2 - Distribuição de frequências observada após classificação em peneiras e distribuição de frequências esperada com base na mensuração da largura (a) ou pela espessura (b) de sementes de Schizolobium parahyba.

Para sementes retidas em peneiras de crivo oblongo o comportamento diferiu-se em relação ao obtido para peneiras de crivo circular (Figura 2b). O teste de Qui-quadrado acusou significância entre as frequências observadas e esperadas, o que indica que ao utilizar este tipo de peneira a classificação de sementes será falha, pois haverá redução de sementes que naturalmente deveriam ocorrer em peneiras de $4 \times 22 \mathrm{~mm}$, bem como o aumento na proporção de sementes retidas em peneiras $5 \times 22 \mathrm{~mm}$.

Tal comportamento apresentado com relação às sementes retidas em peneiras de crivo oblongo caracteriza-se por sua classificação alongadaachatada. As sementes de Schizolobium parahyba apresentam formato irregular geralmente há a ocorrência de algumas deformações ou óbices nas mesmas, podendo interferir e dificultar a peneiração, bem como os demais procedimentos do beneficiamento.

A partir da tabela 2, pode-se visualizar o resumo da ANOVA para o efeito de classificação de sementes sobre os parâmetros morfométricos e de massa de sementes após teste de uniformidade. Houve significância para todos os parâmetros morfométricos e de massa em função da classificação das sementes $(p<0,05)$. Nota-se que o erro experimental foi maior para massa de sementes, cujo coeficiente de variação foi de 8,0\%. Tal evento justifica-se pelo fato de que o estudo teve como base o beneficiamento a partir da morfometria de sementes.

Tabela 2 - Resumo da análise de variância na comparação dos parâmetros morfométricos de sementes de Schizolobium parahyba após teste de uniformidade

\begin{tabular}{lcccc}
\hline \multirow{2}{*}{ F.V } & \multicolumn{4}{c}{ Quadrado médio } \\
\cline { 2 - 5 } & Comprimento & Largura & Espessura & Massa \\
\hline Peneira & $5,669^{* *}$ & $3,978^{* *}$ & $0,212^{* *}$ & $0,142^{* *}$ \\
Erro & 0,145 & 0,045 & 0,015 & 0,020 \\
CV (\%) & 1,3 & 1,2 & 2,6 & 8,0 \\
W (p-valor) & 0,076 & 0,083 & 0,117 & 0,061 \\
B-F (p-valor) & 0,497 & 0,114 & 0,159 & 0,102 \\
\hline
\end{tabular}

NOTA: ** Indicam significância pelo teste $\mathrm{F}$ ao nível de 5\% de probabilidade de erro; CV (\%): coeficiente de variação; W (p-valor): refere-se a probabilidade de significância para normalidade de distribuição dos erros pelo teste de Shapiro Wilk; B-F (p-valor): refere-se a probabilidade de significância para homocedasticidade dos erros pelo teste de Brown-Forsythe.

A partir da figura 3, pode-se visualizar as médias das variáveis estudadas para as sementes de 
Schizolobium parahyba após classificação por peneiras. Observa-se que após a classificação das sementes retidas em peneiras circulares de $14 \mathrm{~mm}$ apresentaram menor comprimento em relação ao tratamento controle (Figura 3a), enquanto que as retidas em crivo circular de $18 \mathrm{~mm}$ o comprimento foi significativamente maior em relação ao tratamento controle (sem classificação), enquanto que para os demais crivos e aberturas não diferiram do tratamento controle.

Nas médias para largura (Figura 3b), notou-se um menor comprimento em sementes retidas em peneira circular de $14 \mathrm{~mm}$ em relação ao tratamento controle, tal que em sementes retidas em crivo circular de $18 \mathrm{~mm}$ foi constatada largura média maior em relação ao tratamento controle. As demais peneiras não apresentaram diferença signifi-
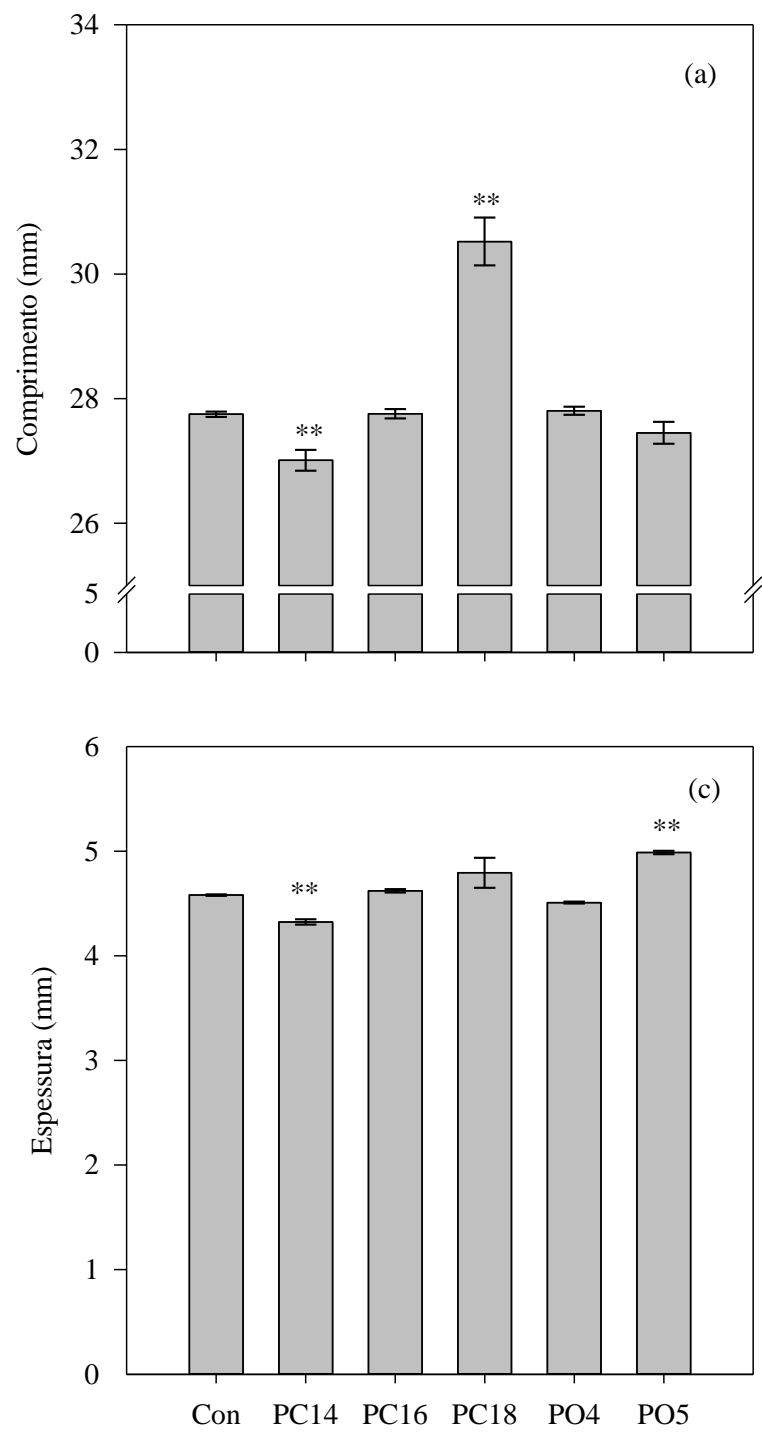

cativa em relação ao tratamento controle.

Para as médias de espessura (Figura 3c), as sementes retidas em peneira circular de $14 \mathrm{~mm}$ apresentaram menor espessura em relação ao tratamento controle, quando as sementes retidas em peneira oblonga 5 × $22 \mathrm{~mm}$ eram mais espessas que no tratamento controle. Por último, nos valores médios de massa (Figura 3d), as sementes retidas em peneira de crivo circular de $14 \mathrm{~mm}$ possuíam menos massa em relação ao tratamento controle, ao passo que sementes retidas em peneiras circulares de $18 \mathrm{~mm}$ e peneiras oblongas de $5 \times 22 \mathrm{~mm}$ portavam massa relativamente maior ao tratamento controle. As sementes retidas nas demais peneiras não apresentaram diferença significativa em referência ao tratamento controle.
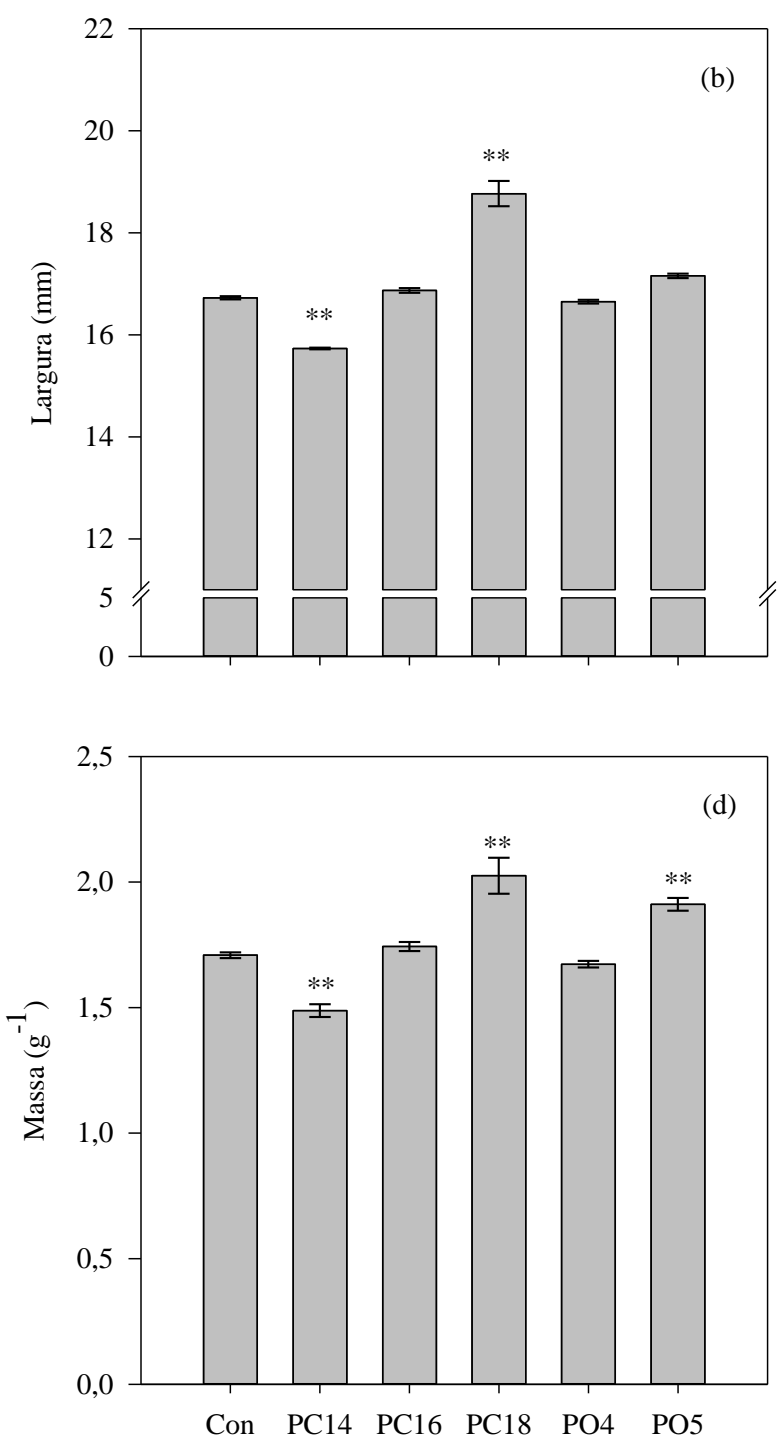

Legenda: Asteriscos indicam diferenças significativas ao nível de 5\% de probabilidade pelo teste Dunnett. Com: controle (sem classificação); P14: Sementes retidas em peneira circular de $14 \mathrm{~mm}$; P16: Sementes retidas em peneira circular de 16 mm; P18: Sementes retidas em peneira circular de 18 $\mathrm{mm}$; PO 4: Sementes retidas em peneira oblonga de 4 × $22 \mathrm{~mm}$; PO 5: Sementes retidas em peneira oblonga de 5 x $22 \mathrm{~mm}$.

Figura 3 - Médias de comprimento (a), largura (b), espessura (c) e massa (d) de sementes de Schizolobium parahyba após teste classificação por diferentes peneiras e crivos. 
Os resultados apresentados na Figura 3 demonstraram que ao classificar sementes de Schizolobium parahyba por peneiras de crivo circular, tanto o comprimento quanto a massa das sementes será uniformizado conjuntamente com a largura das sementes, enquanto que ao utilizar peneiras de crivo oblongo apenas a massa será uniformizada conjuntamente com a espessura das sementes com maiores dimensões.

A partir da Tabela 3, pode-se visualizar o resumo da ANOVA para os parâmetros morfométricos das sementes após teste de uniformidade. Houve significância para todos os parâmetros morfométricos e de massa em função da classificação das sementes $(\mathrm{p}<0,05)$.

Tabela 3 - Resumo da análise de variância na comparação dos coeficientes de variação obtidos para os parâmetros morfométricos de sementes de Schizolobium parahyba após teste de uniformidade

\begin{tabular}{lcccc}
\hline \multirow{2}{*}{ F.V } & \multicolumn{4}{c}{ Quadrado médio } \\
\cline { 2 - 5 } & Comprimento & Largura & Espessura & Massa \\
\hline Peneira & $2,427^{* * *}$ & $5,369^{* *}$ & $14,245^{* *}$ & $25,872^{* *}$ \\
Erro & 0,808 & 0,430 & 1,463 & 4,134 \\
CV (\%) & 20,8 & 21,6 & 22,8 & 20,5 \\
W (p-valor) & 0,085 & 0,073 & 0,201 & 0,379 \\
B-F (p-valor) & 0,167 & 0,641 & 0,063 & 0,701 \\
\hline
\end{tabular}

** Indicam significância pelo teste $\mathrm{F}$ ao nível de 5\% de probabilidade de erro; CV (\%): coeficiente de variação; W (p-valor): refere-se a probabilidade de significância para normalidade de distribuição dos erros pelo teste de Shapiro Wilk; B-F (p-valor): refere-se a probabilidade de significância para homocedasticidade dos erros pelo teste de Brown-Forsythe.

Na figura 4 pode-se visualizar o gráfico de uniformidade para as variáveis testadas após testes de classificação de sementes de Schizolobium parahyba em diferentes peneiras. Para o gráfico de uniformidade em comprimento (Figura 4a) observa-se que houve diferenças nas sementes classificadas em todas as peneiras de crivo circular, em relação ao tratamento controle, enquanto que as peneiras de crivo oblongo não expressaram variação significativa. Da mesma forma, para largura (Figura $4 b$ ) foram identificadas diferenças significativas somente para sementes classificadas em peneiras circulares em relação ao tratamento con-

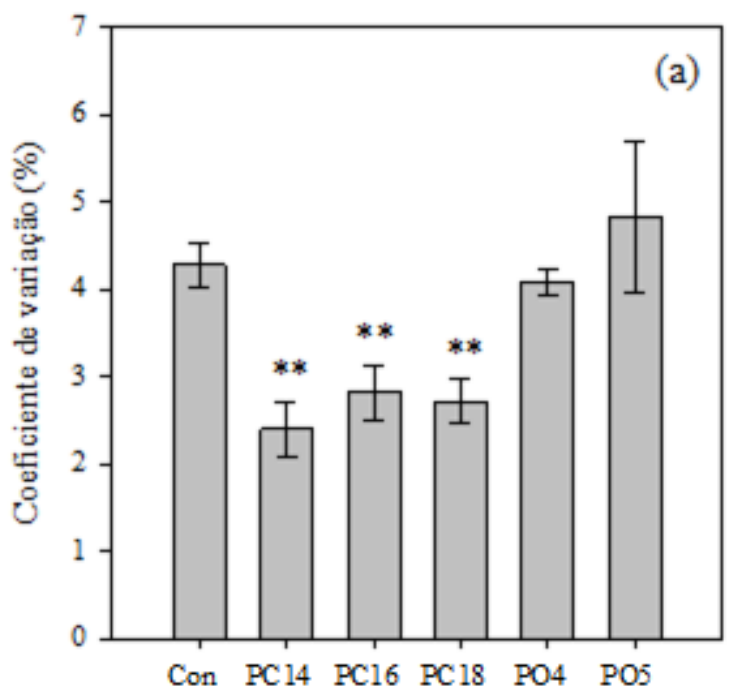

trole.

Em espessura (Figura 4c), as sementes classificadas em peneira de crivo circular de $18 \mathrm{~mm}$ e peneiras de crivo oblongo de 4 × $22 \mathrm{~mm}$ e $5 \times 22$ $\mathrm{mm}$ apresentaram variação significativa quando comparadas ao tratamento controle, ao passo que as demais não mostraram diferença. Por fim, na Figura $4 \mathrm{~d}$, as sementes classificadas em todas as peneiras circulares bem como em peneira de crivo oblongo de $5 \times 22 \mathrm{~mm}$ apresentaram variação significativa para valores de massa. Todavia, as sementes classificadas pelas demais peneiras não expressaram diferença significativa para tal base.

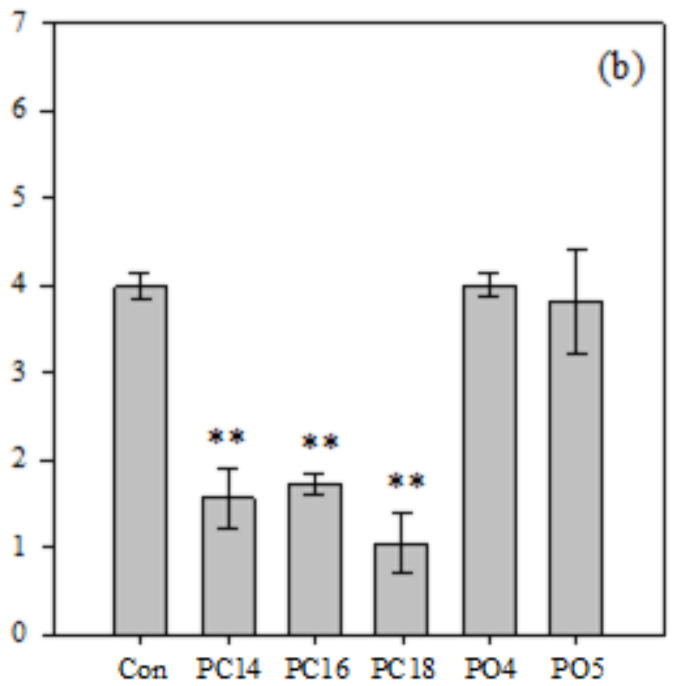

Legenda: Asteriscos indicam diferenças significativas ao nível de 5\% de probabilidade pelo teste Dunnett. Em que: Com: controle (sem classificação); P14: Sementes retidas em peneira circular de $14 \mathrm{~mm}$; P16: Sementes retidas em peneira circular de $16 \mathrm{~mm}$;P18: Sementes retidas em peneira circular de $18 \mathrm{~mm}$; PO 4: Sementes retidas em peneira oblonga de 4 x $22 \mathrm{~mm}$; PO 5: Sementes retidas em peneira oblonga de $5 \times 22 \mathrm{~mm}$

Figura 4 (a e b) - Uniformidade de sementes de Schizolobium parahyba com base no coeficiente de variação após teste classificação por diferentes peneiras e crivos. (a) Comprimento e (b) Largura 

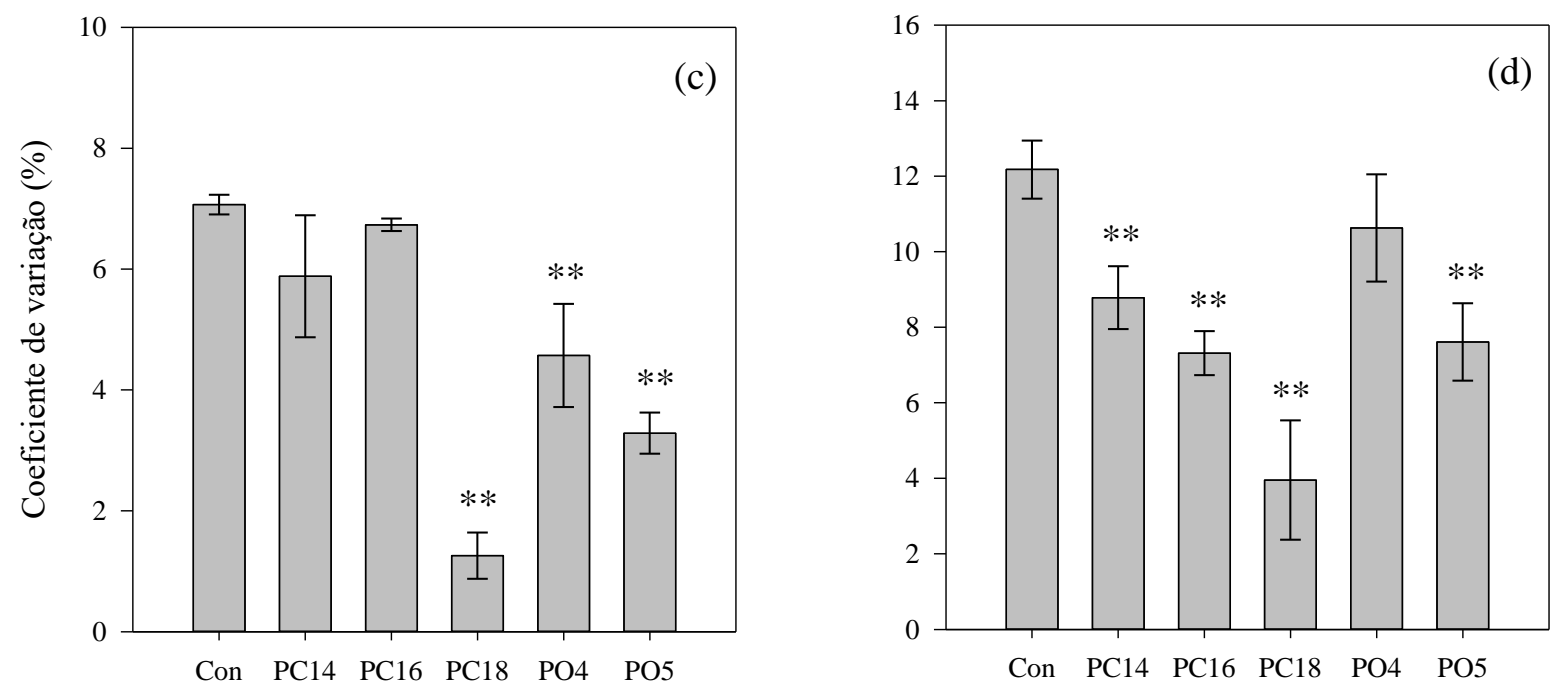

Em que: Asteriscos indicam diferenças significativas ao nível de 5\% de probabilidade pelo teste Dunnett. Em que: Com: controle (sem classificação); P14: Sementes retidas em peneira circular de $14 \mathrm{~mm}$; P16: Sementes retidas em peneira circular de $16 \mathrm{~mm}$;P18: Sementes retidas em peneira circular de $18 \mathrm{~mm}$; PO 4: Sementes retidas em peneira oblonga de 4 x $22 \mathrm{~mm}$; PO 5: Sementes retidas em peneira oblonga de 5 x $22 \mathrm{~mm}$.

Figura 4 (c e d) - Uniformidade de sementes de Schizolobium parahyba com base no coeficiente de variação após teste classificação por diferentes peneiras e crivos. (c) espessura e (d) massa.

\section{CONCLUSÕES}

Para o uso de peneiras na classificação de sementes de Schizolobium parahyba recomenda-se as de crivo circular, pois as sementes dispostas sobre elas escoam facilmente e são retidas nas peneiras conforme seus respectivos tamanhos e tendo a largura como o melhor parâmetro morfométrico para classificação por peneiramento.

\section{REFERÊNCIAS BIBLIOGRÁFICAS}

Antunes LEC, Picolotto L, Vignolo GK, Goncalves MA. Influência do substrato, tamanho de sementes e maturação de frutos na formação de mudas de pitangueira. Revista Brasileira de Fruticultura, v. 34, n. 4, p. 1216-1223, 2012.

Bewley JD, Bradford KJ, Hilhorst HWM, Nonogaki H. Seeds: physiology of development, germination and dormancy. 3 Ed. New York: Springer, 392p. 2013.

Biruel RP, Paula RC, Aguiar IB. Germinação de sementes de Caesalpinia leiostachya (Benth.) Ducke (pau-ferro) classificadas pelo tamanho e pela forma. Revista Árvore, v.34, n.2, p.197-204, 2010. http://dx.doi.org/10.1590/S010067622010000200001

Carvalho PER. Guapuruvu - Taxonomia e Nomenclatura. Colombo: Embrapa Florestas, 10p. 2005.

Cruz ED, Carvalho JEU. Biometria de frutos e sementes e germinação de curupixá (Micropholis $\mathrm{cf}$. venulosa Mart. \& Eichler - Sapotaceae). Acta Amazonica, v.33, n.3, p.389398, 2003. http://dx.doi.org/10.1590/S004459672003000300005

Dranski JAL, Sonda ET, Demarchi Junior JC. Tamanho de sementes e fertilizante de liberação controlada na produção de mudas de Schizolobium parahyba [(Vell.) S. F. Blake)]. Biotemas, v.32, n.2, p.23-31, 2019. https://doi.org/10.5007/2175-7925.2019v32n2p23

Freire JM, Piña-Rodrigues FCM, Santos ALF, Pereira MB. intra-and inter-population variation in seed size and dormancy in Schizolobium parahyba (Vell.) Blake in the Atlantic Forest. Ciência Florestal, v.25, n.4, p.897-907, 2015. http://dx.doi.org/10.5902/1980509820592

Gonzalo DAD, Garcia RJF, Gomes EPC. Avaliação de área recuperada sobre cava de areia em São Paulo, SP, Brasil. Hoehnea, v.42, n.4, p.695-701, 2015. http://dx.doi.org/10.1590/2236-8906-15/RAD/2015

Gusmão E, Vieira FA, Júnior EMF. Biometria de frutos e endocarpos de murici (Byrsonima verbascifolia Rich. Ex A. Juss.). Revista Cerne, v.12, n.1, p.84-91, 2006.

Malavasi UC, Malavasi MM. Influência do tamanho e do peso da semente na germinação e no estabelecimento de espécies de diferentes estágios da sucessão vegetal. Floresta e Ambiente, v.8, n.1, p.211-215, 2001.

Nitsche PR, Caramori PH, Ricce WS,Pinto, LFD. Atlas climático do estado do Paraná. Londrina: Instituto Agronômico do Paraná, 210p. 2019.

Pagliarini MK, Nasser MD, Nasser FACM, Cavichioli JC, Castilho RMM. Influência do tamanho de sementes e substratos na germinação e biometria de plântulas de jatobá. Tecnologia e Ciência Agropecuária, v.8, n.5, p.33-38, 2014.

Peske ST, Labbé LMB. Beneficiamento de sementes. In: Peske ST, Villela FA, Meneghello GE. Sementes: fundamentos científicos e tecnológicos. 3. Ed. Pelotas: Ed. Universitária/UFPEL, p.423-480. 2012. 
Pietrobom RCV, Oliveira DMT. Morfoanatomia e ontogênese do pericarpo de Schizolobium parahyba (Vell.) Blake (Fabaceae, Caesalpinioideae). Revista Brasileira de Botânica, v.27, n.4, p.767-779, 2004.

http://dx.doi.org/10.1590/S0100-84042004000400015

Resende LA, Pinto LVA. Emergência e desenvolvimento de espécies nativas em área degradada por disposição de resíduos sólidos urbanos. Revista Agrogeoambiental, Pouso Alegre, v.5, n.1, p.37-48, 2013.

Sigmaplot. Scientific Graphing Software: Version 12.0. San Rafael: Jandel Corporation, 2011.

Silva KB, Bruno RLA, Melo PAFR. Qualidade fisiológica de sementes de Sideroxylon obtusifolium (Roem. \& Schult.) Penn. classificadas pelo tamanho. Revista Brasileira de Biociências, v.13, n.1, p.1-4, 2015.

Sturges HA. The choice of a class interval. Journal of the American Statistical Association, v.21, n.153, p.65-66, 1926. https://dx.doi.org/10.1080/01621459.1926.10502161

Trianoski R, Iwakiri S, Matos JLM, Prata JG. Avaliação de espécies alternativas de rápido crescimento para produção de painéis de madeira aglomerada de três camadas. Scientia Forestalis, v.39, n.89, p.97-104, 2011.

Tsakaldimi M, Ganatsas P, Jacobs DF. Prediction of planted seedling survival of five Mediterranean species based on initial seedling morphology. New Forests, v.44, n.3, p.327339, 2013. https://doi.org/10.1007/s11056-012-9339-3 